\title{
Abnormal uterine inflammation in obstetric syndromes: molecular insights into the role of chemokine decoy receptor D6 and inflammasome NLRP3
}

\author{
Chiara Tersigni ${ }^{1,2}$, Manu Vatish $^{3}$, and Silvia D'Ippolito ${ }^{1,2}$ \\ Giovanni Scambia ${ }^{2,4}$, and Nicoletta Di Simone (1),
}

\begin{abstract}
'U.O.C. di Ostetricia e Patologia Ostetrica, Dipartimento di Scienze della Salute della Donna, del Bambino e di Sanità Pubblica, Fondazione Policlinico Universitario A. Gemelli IRCCS, Rome 00168, Italy ${ }^{2}$ Università Cattolica del Sacro Cuore, Rome 00168, Italy ${ }^{3}$ Nuffield Department of Women's \& Reproductive Health, University of Oxford, OX3 9DU, Oxford, UK ${ }^{4}$ U. O.C. di Ginecologia Oncologica, Dipartimento di Scienze della Salute della Donna, del Bambino e di Sanità Pubblica, Fondazione Policlinico Universitario A. Gemelli IRCCS, Rome 00168, Italy

*Correspondence address: U.O.C. di Ostetricia e Patologia Ostetrica, Dipartimento di Scienze della Salute della Donna, del Bambino e di Sanità Pubblica, Fondazione Policlinico Universitario A. Gemelli IRCCS, Rome 00I68, Italy. E-mail: nicoletta.disimone@policlinicogemelli.it ORCID (1) orcid.org/0000-0003-1273-3335
\end{abstract}

Submitted on October 4, 2019; resubmitted on December 12, 2019; editorial decision on December 19, 2019

\begin{abstract}
The adaptation of the uterine environment into a favorable immunological and inflammatory milieu is a physiological process needed in normal pregnancy. A uterine hyperinflammatory state, whether idiopathic or secondary to hormonal or organic uterine disorders (polycystic ovary syndromes, endometriosis/adenomyosis and fibroids), negatively influences the interactions between decidua and trophoblast, early in gestation, and between chorion and decidua later in pregnancy. Abnormal activation of uterine inflammatory pathways not only contributes to the pathogenesis of the obstetric syndromes, i.e. recurrent pregnancy loss (RPL), pre-term delivery (PTD) and pre-eclampsia $(\mathrm{PE})$, but also to correlates with severity. In this review, we summarize recent advances in the knowledge of uterine molecular mechanisms of inflammatory modulation in normal pregnancy and obstetric syndromes (RPL, PTD and PE). In particular, we focus on two regulators of uterine/placental inflammation: the NLRP3 inflammasome and the chemokines decoy receptor D6. We performed comprehensive review of the literature in PubMed and Google Scholar databases from 1994 to 2018. The available evidence suggests that: (i) the expression of inflammasome NLRP3 is increased in the endometrium of women with unexplained RPL, in the chorioamniotic membranes of women with PTL and in the placenta of women with PE; (ii) there is a role for abnormal expression and function of D6 decoy receptor at the feto-maternal interface in cases of RPL and PTD and (iii) the function of placental D6 decoy receptor is impaired in PE. A wider comprehension of the inflammatory molecular mechanisms involved in the pathogenesis of the obstetric syndromes might lead to the identification of new potential therapeutic targets.
\end{abstract}

Key words: pregnancy / inflammatory response / cytokines / decoy receptor D6 / inflammasome NLRP3

\section{Introduction}

Human pregnancy is an inflammatory process; starting before conception and terminating with delivery. Menstrual cycle-dependent inflammatory modulation of the human endometrium plays a pivotal role in creating an appropriate environment to receive the conceptus. Similarly, implantation and invasion of the endometrium and spiral arteries by the extra villous cytotrophoblast require cytokines and chemokines from immune cells (natural killer cells, macrophages and dendritic cells) for tissue remodeling and placentation (Moffett-King, 2002; Sargent et al., 2006; Mor et al., 20II). Once pregnancy has established, the developing placenta takes an extraordinary and complex part in orchestrating maternal immune tolerization of the semiallogeneic fetus as well as inflammatory control of maternal tissues. The interaction between the placenta and membranes of the fetus, with the maternal endometrium and immune cells located therein must be finely controlled to achieve a successful pregnancy outcome. Thus, in the context of pregnancy, inflammation is a physiological requirement 
in normality, but when aberrant can drive significant pregnancy complications ranging from miscarriage to placental insufficiency.

Recently, the expression and function of the inflammasome NLRP3 and the chemokine scavenger decoy receptor D6 in endometrial and placental tissues, involved in controlling the inflammatory response, have been investigated. That has allowed better definitions of their roles in normal pregnancy and in obstetric syndromes like unexplained recurrent pregnancy loss (RPL), pre-term delivery (PTD) and preeclampsia (PE).

The aim of this review is to summarize recent advances in understanding molecular mechanisms of uterine inflammatory modulation in normal and pathological pregnancy. Defining pathogenic mechanisms, indeed, represents the first step to develop new therapeutic targets and, thus, successful modern personalized medicine.

\section{Methods}

Using PubMed and Google Scholar databases, we performed comprehensive literature searches in the English language for studies on the role of inflammasome NLRP3 and D6 decoy receptor in both normal pregnancy and obstetric syndromes (RPL, PTD and PE). We used the search terms 'RPL,' 'PTD,' 'PE,' 'inflammation,' 'chemokines,' 'scavenger D6,' 'inflammasome NLRP3' and combinations of these. Articles from 1994 to 2018 were screened for relevance, validity and quality.

\section{Inflammasome NLRP3}

Inflammasomes are high molecular weight, intracellular multiprotein complexes that form a scaffold enabling caspase-mediated processing of the proinflammatory cytokines of the interleukin (IL)-I family (Martinon et al., 2002). They represent the first line of defense against microbial invasion and cellular stress constituting a crucial component of innate immunity. The specific sequence of protein interactions initiated in assembling the inflammasomes follows receipt and decoding of a diverse array of triggers, coming from micro-organisms (PAMPs - pathogen associated molecular patterns) or damaged tissues (DAMPs - damage associated molecular patterns) and binding to target pattern recognition receptors, the toll-like receptors (TLRs) (extensively reviewed in Khan et al., 20I5). Inflammasomes typically form from the induced assembly of caspase- I, a NOD-like receptor or NLR (NOD meaning nucleotide-binding oligomerization domain) and an adaptor protein, ASC (apoptosis-associated speck-like protein with caspase activation and recruitment domain - CARD) (Martinon et al., 2002; Mariathasan et al., 2006). Following inflammasome assembly, the resultant oligomeric construction yields a transient platform that enables a sequence of enzymatic reactions exemplified by autocatalysis of the inflammatory caspases (caspase- I) and its proteolysis of proforms of the $\mathrm{IL}-\mathrm{I} \beta$, and $-\mathrm{I} 8$ to generate their respective mature, secretory forms (Fig. I).

Currently, four main types of inflammasomes have been characterized, of which the NLRP3 family is the most investigated and it is known to be abundantly expressed in the human endometrium and placenta (www.proteinatlas.org/ENSG00000 I627I I-NLRP3/tissue). The role of NLRP3 inflammasome activation has been shown in the pathogenesis of a wide range of pathologies such as arthritis, cardiovascular disease and metabolic syndromes. Only in the last decade, involvement of inflammasome NLRP3 activation at human maternal-fetal interface in the pathogenesis obstetric syndromes, particularly in RPL, PTD and PE, has been proposed (see more below).

\section{Chemokine decoy receptor D6}

The uterine inflammatory response is mediated by several mediators such as chemokines (Luster, 1998; Charo and Ransohoff, 2006), which promote leukocyte recruitment to sites of infection and inflammation by activating conventional G protein-coupled receptors (Murphy, 1994; Murphy et al., 2000). Chemokines are also recognized by a set of atypical chemokine receptors (ACRs) required for the generation of chemokine gradients in tissues (Locati et al., 2005; Mantovani et al., 2006). D6 decoy receptor is one of the ACRs. It binds most inflammatory CC chemokines, internalizes constitutively and targets the ligand for degradation in lysosomal compartments (Bonecchi et al., 2004; Galliera et al., 2004), while the receptor is free to recycle back to the cell surface (Fra et al., 2003; Weber et al., 2004; Bonecchi et al., 2008) with mechanisms that are strictly dependent on cytoskeleton dynamics (Borroni et al., 20I3) (Fig. 2A). In resting conditions, D6 is predominantly located in intracellular/perinuclear compartments and only 5\% is detectable on the cell surface (Blackburn et al., 2004; Weber et al., 2004). D6 expression has been reported mainly in non-hematopoietic cells and includes endothelial cells lining afferent lymphatic in skin, gut and lung (Nibbs et al., 200 I). D6 expression has also been detected in trophoblast-derived cells in human placenta, decidua and gestational membranes throughout pregnancy, with specific intracellular distribution patterns (Nibbs et al., 1997; Madigan et al., 20 I0).

A role for D6 in the maintenance of a controlled inflammatory environment at the maternal-fetal interface has been proposed by Martinez de la Torre and co-authors, who showed that extravillous trophoblasts and syncytiotrophoblast cells express D6 and use this molecule to scavenge pro-inflammatory CC chemokines (Martinez de la Torre et al., 2007). Intriguingly, they also provided evidence that D6 is required to prevent excessive placenta leukocyte infiltration and inflammation, as well as autoantibody-induced fetal loss in animal models (Martinez de la Torre et al., 2007). Consistently, Madigan et al. have demonstrated that, in normal pregnancy, despite robust expression of pro-inflammatory chemokines by gestational tissues, D6binding chemokines are less abundant in maternal plasma compared to non-pregnant women. Indeed, maternal blood continuously flows toward D6-expressing chorionic villi, suggesting a crucial role for D6 decoy receptor in blood chemokines scavenging and regulation of local and systemic inflammation (Madigan et al., 20l0).

\section{Inflammation and recurrent pregnancy loss}

RPL occurs in 3-5\% of all women and is defined by three consecutive pregnancy losses prior to 23 weeks of gestational age (Ford, 2009). Unfortunately, only in $60 \%$ of couples one or more causes can be identified to justify their losses. Indeed, in about $40 \%$ of all RPL cases, after a complete screening for the known causes or predisposing factors, none of the above anomalies can be found, identifying cases of idiopathic RPL (Ford, 2009). Several studies suggest that 


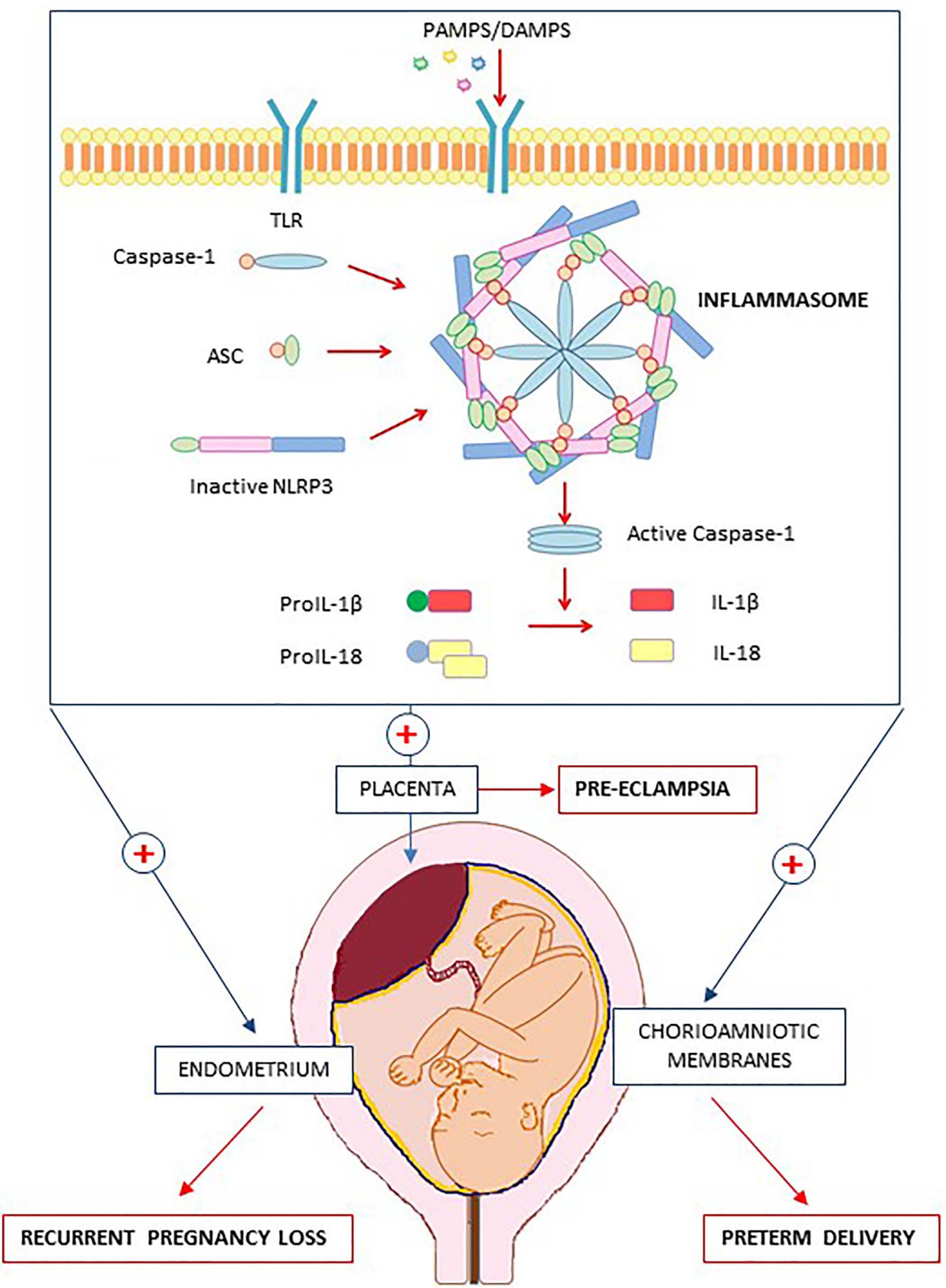

Figure I Schematic illustration of the NLRP3 inflammasome activation in maternal-fetal tissues. Several triggers PAMPs or DAMPs can induce inflammasome activation through TLR binding. Once the inflammasome has assembled secretions of the pro-inflammatory IL-I $\beta$ and 18 ensues. Tissue inflammatory response ensues, at level of endometrium, early in pregnancy, or later, at level of chorion-amniotic membranes and/or in placental tissues, contributing to the occurrence of RPL, PTD or PE, respectively. ASC, apoptosis-associated speck-like protein with CARD domain. 


\section{A. NORMAL PREGNANCY}

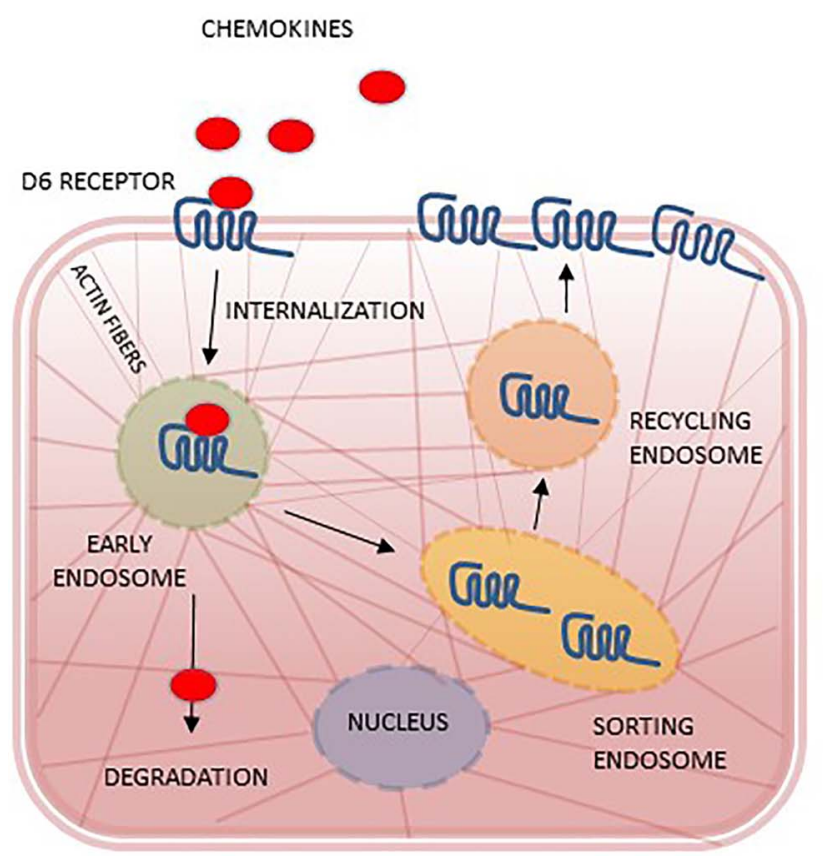

B. PRE-ECLAMPSIA

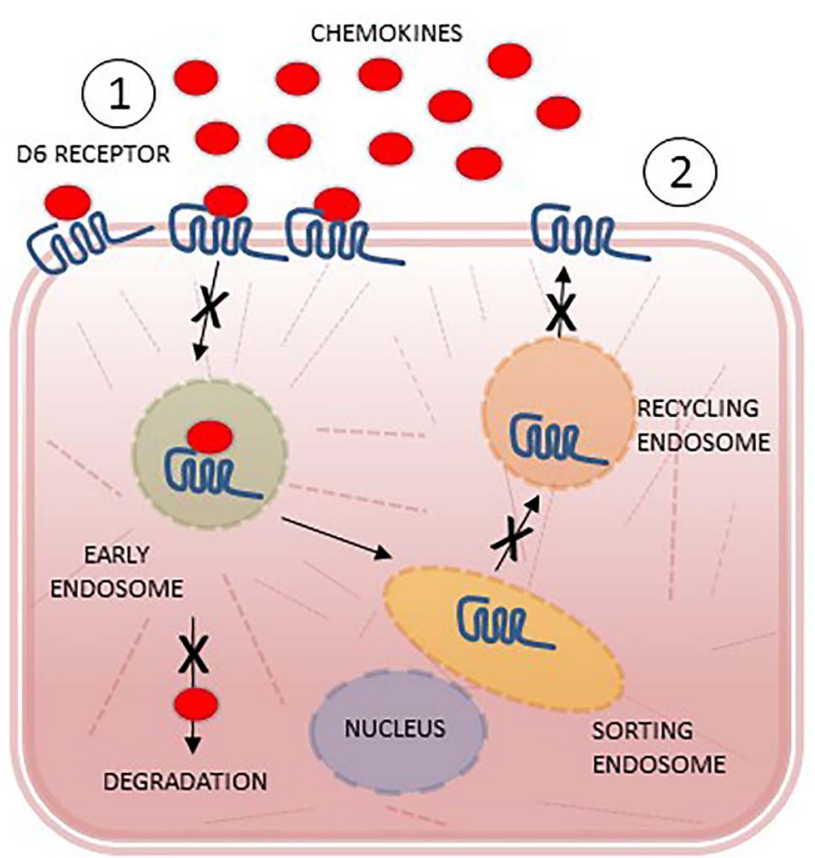

TROPHOBLAST CELLS

Figure 2 D6 decoy receptor chemokines scavenging function in trophoblast cells from normal pregnancy and PE. (A) In normal pregnancy, D6 decoy receptor binds chemokines and internalizes D6-ligand complex in early endosome to separately sorting, on one hand, chemokines to lysosomal degradation and, on the other hand, D6 receptor to recycling, through endosomes. (B) Proposed mechanism of D6 function impairment in PE: because of higher tissue concentrations of chemokines, D6 receptor is mostly mobilized on apical side of trophoblast membranes (I) but progressive cytoskeleton disarrangement, induced by the oxidative stress of trophoblast cells, dramatically limits chemokines degradation as well as receptor recycling (2). Other unknown mechanisms of placental D6 impairment might concomitantly occur in PE.

women with RPL have a greater bias toward a Thl-type or proinflammatory cytokine profile (Raghupathy et al., 2000; Jenkins et al., 2000) as compared to normal pregnancy, which has been characterized as a Th2-dominant state (Wilczynski, 2005). In particular, an abnormal endometrial inflammation, in absence of detectable infectious causes, might be one of the pathogenic mechanisms involved in determining unreceptive endometrium, potentially leading to early fetal loss.

\section{Lipopolysaccharide-triggered activation of endometrial NLRP3 in recurrent pregnancy loss}

Consistent with the hypothesis of a causal role of uterine 'inflamed' environment at the basis of early reproductive failure, endometrial upregulation of pro-inflammatory cytokines (IL-I $\beta, \mathrm{TNF}-\alpha, \mathrm{IFN} \gamma$ and TGF- $\beta$ I) secretion has been shown in women with idiopathic RPL (Banerjee et al., 20I3). In support, we demonstrated an abnormal activation of the endometrial inflammasome NLRP3 and higher tissue levels of caspase-I, IL-I $\beta$ and IL-I8 in women with idiopathic RPL
(D'lppolito et al., 20|6). More recently, we have observed a higher prevalence of abnormal intestinal permeability in patients with idiopathic RPL (Tersigni et al., 20 I8). In the same population, we detected higher plasma levels of lipopolysaccharide (LPS), an immunogenic parietal fragment from Gram-negative bacteria and powerful activator of inflammasome. For the first time, we could link endometrial NLRP3 inflammasome over-activation with leaky gut (Tersigni et al., 20 I8), defined by increased intestinal permeability due to epithelial barrier breakdown, secondary to different pathological conditions (celiac disease, food allergies, intestinal bowel diseases, etc.) (Camilleri, 2019). Based on these evidences, we can speculate that in women with RPL bacterial components might enter systemic circulation through a damaged intestinal barrier and induce widespread secretion of proinflammatory cytokines, particularly into delicate endometrial tissues, via inflammasome NLRP3 activation. Hence, increased intestinal permeability and/or higher circulating levels of LPS could confer a higher risk of endometrial inflammation and reproductive disorders. Crosstalk between the gut and the reproductive system may be an intriguing hypothesis to be further investigated in a larger cohort of population of RPL. That could open new perspectives of personalized diagnostic and therapeutic approaches to patients with idiopathic RPL. Furthermore, since RPL is a syndrome with a multifactorial pathogenesis, further 
investigation is needed to clarify whether different triggers, other than LPS associated to leaky gut, might be responsible for endometrial inflammasome activation in RPL.

\section{Role of chemokine decoy receptor D6 in recurrent pregnancy loss}

The role of D6 in the pathogenesis of pregnancy loss, to our knowledge, has not been specifically investigated in humans yet. However, a study conducted on pigs by Wessels and co-workers described the expression of the decoy receptors D6, Duffy antigen receptor for chemokines (DARC) and Chemocentryx decoy receptor (CCX CKR) at the porcine feto-maternal interface (Wessels et al., 2007, 20II). The authors demonstrated dysregulation of DARC and CCX CKR but not D6 transcripts in endometrium and trophoblasts obtained from cases of fetal loss. However, no differences were found in terms of decoy receptors proteins or ligands (CCL2, CCL3, CCL4, CCL5, CCLII, CCL19, CCL2I, CXCL2 and CXCL8) expression at fetomaternal interface between healthy and arresting conceptuses (Wessels et al., 2007, 20 I I). In addition, an interesting study conducted on DBA/Ij mice has shown that D6 deficiency increases levels of plasma CCL2, the incidence of stillbirth and neonatal death and decreases placental size and fetal weight (Teoh et al., 20l4).

Studies on human tissues are needed to establish whether abnormal synthesis or functionality of decoy receptors might have a role in the pathogenesis of RPL.

\section{Inflammation and preterm delivery}

PTD, defined as delivery prior to the 37 th week of gestation, is the leading cause of perinatal morbidity and mortality worldwide (Liu et al., 2015). In Western countries, about 10\% of all births are classified as preterm, and in developing countries, this percentage is even higher (Martin et al. 2016). Preterm neonates are at increased risk of shortand long-term morbidities and, thus, prematurity places a substantial burden on the healthcare system and society (Behrman and Butler, 2007; Lubow et al., 2009; Mwaniki et al., 20 I2; Manuck et al., 20 I4). Two-thirds of PTDs occur after spontaneous preterm labor (Goldenberg et al., 2008), while one-third are iatrogenic. Spontaneous preterm labor is a syndrome associated with multiple pathological processes (Romero et al., 20 I4), such as intra-amniotic inflammation (IAI), which has been causally linked to PTD (Gravett et al., 1994; Baggia et al., 1996; Sadowsky et al. 2006; Presicce et al., 20I5). IAI can be due to microorganisms (bacteria, viruses or fungi) or endogenous danger signals derived from necrosis or cellular stress (already mentioned DAMPs) (Matzinger et al., 1998; Jacobsson, 2005; Oppenheim and Yang, 2005; Lotze et al., 2007; Romero et al., 2007). The infectioninduced IAI reported in cases of PTD has been associated with histologic chorioamnionitis (Gargano et al., 2008) and higher placental and circulating levels of ThI type ILs (El-Shazly et al., 2004; Gargano et al., 2008). On the other hand, the pro-inflammatory reaction occurring when microorganisms cannot be detected by common cultivation and molecular microbiology techniques (Romero et al., 20I4a,b, 20I5a,b,
2016) are likely to be induced by DAMPs (Chen and Nunez, 20I0). Clinicians and scientists commonly consider the latter cases, accounting for the $50 \%$ of cases of spontaneous PTD, as due to 'sterile inflammation.' Interestingly, sterile IAI seems to be more common than microbial associated IAI in patients with preterm labor and intact chorioamniotic membranes (Romero et al., 20 I4b). However, it is likely that the theory of sterile inflammation in PTD might be soon revised through the development of the extremely sensitive next generation sequencing (NGS) techniques. Indeed, NGS has allowed to detect and describe the huge and unknown world of the microbiota, potentially acting as PAMPs, in organs like the uterus, previously erroneously considered sterile (extensively reviewed in Baker et al., 20।8).

\section{Role of inflammasome NLRP3 in preterm delivery}

There are several indirect lines of evidence suggesting a role for exaggerated inflammasome activity in the pathogenesis of PTD in humans. In chorioamniotic membrane extracts from women who underwent spontaneous PTD, higher concentrations of high mobility group box-I (HMGBI) have been shown compared to women with spontaneous labor at term (Plazyo et al., 2016). HMBGI is a chromatin-binding protein belonging to alarmin family, whose release occurs downstream of inflammasome assembly and caspase I activation (Lamkanfi et al., 20I0). During infection or injury, activated immune cells and damaged cells release HMGBI into the extracellular space, where HMGBI functions as a proinflammatory mediator and contributes importantly to the pathogenesis of inflammatory diseases. Interestingly, it has been shown that incubation of the chorioamniotic membranes with HMGBI upregulates the mRNA and protein expression of the inflammasome components NLRP3 and induces the release of mature caspase-I and IL-I $\beta$ (Plazyo et al., 20|6), suggesting a positive feed-back of HMGBI on NLRP3 activation. Consistent with this idea, higher levels of HMGBI have been found in amniotic fluid of women with preterm premature rupture of membranes compared to those with PTD with intact membranes (Romero et al., 20 I I). Levels of caspaseI, the final product of inflammasome activation, were augmented in amniotic fluid from women with PTD with confirmed intrauterine infection compared with women delivering at term or preterm without infection (Gotsch et al., 2008), suggesting a stronger inflammasome involvement in cases of infection-induced PTD. Consistently, elevated mid-trimester concentrations of IL- 18 have been identified in amniotic fluid of women subsequently developing intra-amniotic infection and spontaneous PTD (Deskalakis et al., 2009).

Recently, Gomez-Lopez and co-workers observed that the chorioamniotic membranes from women with spontaneous PTD and histologic evidence of acute chorioamnionitis express higher concentrations of inflammasome components (caspase-I and -4, ASC/CASP-I complex IL-I $\beta$ and - 18) compared to those from women with PTD without this placental lesion (Gomez-Lopez et al., 2017).

More recently, Faro and coauthors, using an animal model of LPSinduced IAI, demonstrated that there was priming of the NLRP3 inflammasome at transcriptional level, indicated by enhanced mRNA expression of inflammasome-related genes (NLRP3, CASPI and ILI $\beta$ ) and NLRP3 protein level in both the fetal membranes and decidua basalis prior to PTD (Faro et al., 20 I 9). Finally, using the specific NLRP3 inhibitor, MCC950, the same authors showed that in vivo inhibition 
of the NLRP3 inflammasome reduced IAI-induced PTD and neonatal mortality (Faro et al., 2019; Gomez-Lopez et al., 2019).

Collectively, these results suggest that NLRP3 inflammasome activation is involved in the innate inflammatory response occurring in the chorioamniotic membranes in cases of infection-induced PTD, contributing to the occurrence of chorioamnionitis lesions and IAI. Bacterial infections may obviously be the first trigger for inflammasome assembly (LPS is its most powerful activator) and, as aforesaid, are responsible of the $50 \%$ of cases of PTD. However, it is likely that the inflammasome NLRP3, which can be activated by DAMPs too, may be also involved in the occurrence of sterile inflammation and contribute to the pathogenesis of cases PTD not associated to infections. Further research is required to define the role of inflammasome NLRP3 in the cascade leading to the tissue inflammatory response in both infectioninduced and sterile PTD. Encouraging therapeutic perspectives might open, since it has been shown that by targeting the NLRP3 inflammasome, adverse pregnancy and neonatal outcomes can be significantly reduced (Faro et al., 2019; Gomez-Lopez et al., 2019).

\section{Role of chemokines in preterm delivery}

A clear role of D6 decoy receptor or other atypical decoy receptors in the pathogenesis of PTD has not been demonstrated yet. However, the search for maternal markers of PTB has identified increased expression of D6-specific chemokines like CXCL8 in cervical mucus, and CCL2 (also known as macrophage migration inhibitor factor or MIF) in maternal serum or amniotic fluid (Sakai et al., 2004; Esplin et al., 2005; Pearce et al., 2008). Consistently, higher levels of the D6-specific chemokines CCL5, CCL7 CCL8, CCL20 and CXCL5 in amniotic fluid has been associated with microbial invasion and amniotic cavity inflammation during preterm labor (Jacobsson et al., 2005; Hua et al., 20 I2; Lappas, 2012; Hamilton et al., 2013). Based on these observations, we can speculate that increased levels of chemokines in amniotic fluid might be the consequence of the inflammatory response to bacterial colonization of amniotic cavity. However, in cases of PTD not associated to intra-amniotic infections, an abnormal scavenging function of D6 decoy receptor, constitutive or acquired, might play a role in causing tissue inflammation of feto-maternal unit, thus contributing to the pathogenesis of PTD. Further investigation is mandatory to clarify the role of chemokines decoy receptors in this syndrome.

\section{Inflammation and pre-eclampsia}

$\mathrm{PE}$ is a pregnancy-specific hypertensive disorder defined as new onset hypertension and proteinuria at or after 20 weeks' gestation (Khan et al., 2006). Complicating 2-8\% of all pregnancies, PE is a major cause of maternal morbidity and mortality and of adverse perinatal outcomes (Duley et al., 2006). The mechanisms underlying PE remain incompletely investigated and delivery remains the only known cure. PE can occur at early gestation $(<34$ weeks) or with a late onset (>34 weeks). The placenta plays a role in the initiation of both early and late onset PE but by different mechanisms. Early onset PE is recognized to be a placenta-driven disorder resulting from deficient placentation occurring in the first half of pregnancy. At this stage, PE does not clinically manifest (first stage). Late onset, PE is also placenta in origin but is thought to occur as a result of villus overcrowding (Redman et al., 2014). PE becomes overt when utero-placental malperfusion and syncytiotrophoblast oxidative stress occur due to the ever more perfusion requirement of the growing feto-placental unit. Then, the 'stressed' syncytiotrophoblast releases into the maternal circulation anti-angiogenic factors and high concentrations of syncytiotrophoblastderived extracellular vesicles (STEVs), causing endothelial dysfunction, exaggerated maternal inflammatory response and hypercoagulability (Redman et al., 1999; Redman and Sargent, 2005). Thus, PE exhibits many of the classical features of inflammation (Redman et al., 1999; Redman and Sargent, 2003) that is responsible for mediating, or at least worsening, the clinical severity of the syndrome.

\section{Role of inflammasome NLRP3 in pre-eclampsia}

As mentioned previously, one of the main features of PE is the imbalance between pro- and anti-inflammatory cytokines and a switch of the immunologic balance toward a Thl-type immunity (Saito and Sakai, 2003; Szarka Aet al., 20I0). Such a pro-inflammatory status is associated with high plasma levels of uric acid and IL-I $\beta$. A potential involvement of the inflammasome in the pathogenesis of $\mathrm{PE}$ has been suggested since metabolites able to activate this protein complex are characteristically augmented in the circulation of women affected from this syndrome. In particular, raised plasma levels of uric acid are often apparent before clinical signs of the disease (Koopmans et al., 2009; Gowri and Al-Zakwani, 20I0). Since the placenta seems to play a pivotal role in the pathogenesis of $\mathrm{PE}$, the expression of genes and proteins related to the inflammasome have been recently investigated at feto-maternal interface. In human first trimester villous trophoblast and two trophoblast cell lines (Sw.7I and HTR$8 /$ SVneo), monosodium urate promoted IL-I $\beta$ secretion via NLRP3inflammasome activation indicative of its proinflammatory effects (Mulla et al., 20 I I). In two intriguing studies of Vikki Abrahams' group, performed on human first trimester trophoblast cells, the NLRP3 inflammasome was proposed to be implicated in the antiphospholipid antibodies (aPL)-induced recurrent miscarriage (Mulla et al., 201 I, 20I3). In particular, they have demonstrated that aPL antibodies, via TLR-4 activation, induce a uric acid response in human trophoblast, which in turn activates the NLRP3 inflammasome leading to IL-I $\beta$ processing and secretion. This novel mechanism may account for the inflammation at the maternal-fetal interface, which causes placental dysfunction and increases the risk of adverse pregnancy outcome in patients with aPL antibodies syndrome. More recently, a pilot study performed on placental tissues from women with normotensive pregnancy or women with PE showed a significant increase of NLRP3, caspase-I and IL-I $\beta$ expression in PE women (Weel et al., 20I7). Furthermore, since there is an increased shedding of STEVs from the placenta into the maternal circulation in PE (Sargent et al., 2003), it is conceivable that DAMPs carried by STEVs might induce inflammasome activity in several cell types (endothelium, blood cells, etc.) and enhance maternal inflammatory response. Consistently, in an elegant murine study performed by Kohli and coworkers, mouse endothelial-derived EVs were shown to cause accumulation of activated platelets within the placental vascular bed. That phenomenon was associated to plateletdependent placental inflammasome NLRP3 activation, triggering PE-like phenotype. Intriguingly, both genetic and pharmacological inhibition of placental inflammasome activation abolished the PElike phenotype pointing to EVs-induced inflammasome activation as 
Table I Evidence for the involvement of NLRP3 inflammasome and D6 decoy receptor, and related cytokines, in the pathogenesis of RPL, PTD and PE.

\begin{tabular}{|c|c|c|c|}
\hline & NLRP3 inflammasome & D6 decoy receptor & Cytokines involved \\
\hline Recurrent pregnancy loss & $\begin{array}{l}\uparrow \text { Expression and activation of } \\
\text { NLRP3 in human endometrium }\end{array}$ & $\begin{array}{l}\text { Higher prevalence of fetal loss in } \\
\text { D6-deficient mice }\end{array}$ & $\begin{array}{l}\text { Caspase- I, IL- } \mid \beta \text { and IL- I 8; CCL2 } \\
\text { (murine model) }\end{array}$ \\
\hline Pre-term delivery & $\begin{array}{l}\uparrow \text { Caspase- I and IL-I } 8 \text { in human } \\
\text { amniotic fluid; } \\
\uparrow \text { Caspase-I, IL-I } \beta \text { and IL-I } 8 \text { in } \\
\text { human chorio-amniotic membranes }\end{array}$ & $\begin{array}{l}\uparrow \text { D6-specific chemokines in human } \\
\text { cervical fluid, serum and amniotic } \\
\text { fluid }\end{array}$ & $\begin{array}{l}\text { Caspase- I, IL-I } \beta \text { and IL-I8; CCL2, } \\
\text { CXCL8, CCL5, CCL7 CCL8, CCL20 } \\
\text { and CXCL5 }\end{array}$ \\
\hline Pre-eclampsia & $\begin{array}{l}\uparrow \text { Expression of NLRP3, caspase-I } \\
\text { and IL-I } \beta \text { in human placenta }\end{array}$ & $\begin{array}{l}\uparrow \text { D6-specific chemokines in human } \\
\text { serum; } \downarrow \text { Chemokines scavenging } \\
\text { function in human placenta }\end{array}$ & $\begin{array}{l}\text { Caspase- I, IL-I } \beta, \mathrm{IL}-6, \mathrm{C} \text { reactive } \\
\text { protein; } \mathrm{CCL}-2, \mathrm{CCL}-7 \text { and } \mathrm{CCL}-\mathrm{II}\end{array}$ \\
\hline
\end{tabular}

a central mechanism in the pathogenesis of the obstetric syndrome and uncovering a novel thrombo-inflammatory mechanism at the fetomaternal interface (Kohli et al., 20|6).

\section{Role of chemokine decoy receptor D6 in pre-eclampsia}

The systemic inflammatory response occurring in overt PE involves leukocytes, endothelial cells, the coagulation cascade and the complement system (extensively reviewed in Redman and Sargent, 2003). A large variety of soluble pro-inflammatory proteins, such as chemokines, mediates the communication between the various components of this inflammatory network (Luster, 1998; Charo and Ransohoff, 2006). In particular, women affected by PE show higher plasma levels of the D6 specific-ligand CCL-2 (or MIF) compared to normal pregnant women (Todros et al., 2005). Recently, we have investigated the expression and function of chemokines D6 decoy receptor in the placentae of women who developed PE. Higher circulating levels of both D6specific chemokines, like CCL-7 and CCL-II, and pro-inflammatory cytokines, like IL- 6 and $C$ reactive protein, were found in serum of pre-eclamptic compared to healthy pregnant women (Tersigni et al., 2016). It is of note that in cytotrophoblast cells isolated from normal placentae, D6 receptor was found to be mainly localized in intracellular compartments, consistent with previous reports (Madigan et al., 20 I 0), while in PE, D6 showed a characteristic distribution on cytotrophoblast cell membranes. In addition, in trophoblast cells from PE, the phosphorylation of LIMKI and cofilin was over-activated compared to controls. This is the intracellular signaling occurring downstream D6 receptorligand interaction on cell membrane. It is required for actin depolymerization and cytoskeleton rearrangement, which is essential for chemokines degradation by D6 receptor and its recycling from intracellular pool to cell membrane. The observation of an increased phosphorylation of LIMKI and cofilin in trophoblast cells from PE is coherent with the increased relative abundance of D6-specific chemokines (like CCL-2, CCL-7 and CCL-II), which are expected to be in trophoblast extracellular environment in PE (Tersigni et al., 2016). Indeed, in PE circulating levels, chemokines are increased, thus trophoblast D6 receptor is expected to be saturated, which is consistent with the downstream intracellular signaling over-activation. In contrast, functional assays of D6 receptor have shown a significant decrease of CCL2 scavenging activity in cytotrophoblast cells obtained from PE women compared to cells from normal placentae. This may be secondary to significant cytoskeletal disarrangement, which was noted in PE trophoblast compared to controls (Tersigni et al., 2016). Decreased expression of placental D6 decoy receptor at both transcriptional and protein levels has also been reported in PE (Cho et al., 20I5), although we could not confirm this observation in our studies (Tersigni et al., 20 I6). Our hypothesis is that in PE, higher circulating and placental levels of pro-inflammatory chemokines might bind to syncytiotrophoblast membrane D6 decoy receptor, inducing an increased concentration of the scavenger on the syncytiotrophoblast cell membranes, due to its mobilization from the intracellular pool (Fig. 2B). Concomitantly, the occurrence of trophoblast cells cytoskeleton damage, likely due to syncytiotrophoblast oxidative stress (Bonecchi et al., 2008; Ganguly et al., 20II), affects D6 function, overstressed by the increased chemokines levels. This hypothesis is consistent with the observation in vitro of higher expression of D6 but lower scavenging of exogenously added CCL-2 in cytotrophoblast membranes isolated from PE placentae. In conclusion, syncytiotrophoblast stress and cytoskeleton impairment might take place, at different times, in both early and late PE, impairing cell cytoskeleton, D6-mediated chemokines degradation and D6 receptor recycling, thus causing deficient regulation of inflammatory environment at maternal-fetal interface.

Further studies are needed to clarify the D6 scavenging function in the pathogenesis of PE and to investigate new potential therapeutic perspectives targeting D6 molecular system. Indeed, it is reasonable to speculate that improving D6 function might attenuate, the exaggerated inflammatory response occurring in $\mathrm{PE}$.

\section{Conclusions}

Excessive inflammatory response and abnormal expression and/or function of the inflammasome NLRP3 and the decoy receptor D6 are involved in the pathogenesis of the most severe pregnancy complications (Table I). In view of the sheer diversity of DAMPs or pathogens bacteria in the genital tract potentially stimulating the immune system in pregnancy, investigating how inflammasomes and chemokines decoy receptors are enlisted to drive or limit uterine inflammation in pregnancy will help in elucidating mechanisms underlying the great obstetric syndromes. Furthermore, the understanding of uterine molecular modulation of inflammation could provide new therapeutic targets for pregnancy disorders. We are currently 
evaluating the effect of anti-inflammatory drugs on D6 function in trophoblast cells with encouraging results, in particular, in preventing cytoskeleton disarrangement (unpublished data). Furthermore, among many inhibitors of NLRP3 inflammasome complex proposed in the last years (Ahn et al., 20l8), the sequencing and therapeutic application of silencing micro RNAs, affecting proteins expression and activation, currently represents the most promising therapeutic perspective (Pacifico et al., 2017). Nonetheless, we are still far from full comprehension of the pathogenesis of the obstetric syndrome and from clinical application of mechanism-specific therapies in obstetrics. Further efforts in terms of biomedical research are needed.

\section{Acknowledgements}

We thank the Italian 'Ministero dell'Istruzione, dell'Università e della Ricerca' (MIUR), the 'Università Cattolica del Sacro Cuore' of Rome, Italy, and the charity Mia Neri Foundation Onlus for supporting our research.

\section{Authors' roles}

CT: conception and design of the work; drafting the work and the images; final approval of the version to be published. MV: revising the work critically for important intellectual content; final approval of the version to be published. SD: contribution to the conception and the design of the work; drafting the work; final approval of the version to be published. GS: revising the work critically for important intellectual content; final approval of the version to be published. NDS: contribution to the conception and the design of the work; revising the work critically for important intellectual content; final approval of the version to be published.

\section{Funding}

This research received no specific grant from any funding agency in the public, commercial or not for-profit sectors.

\section{Conflict of interest}

The authors declare no conflicts of interests.

\section{References}

Ahn H, Kwon HM, Lee E, Kim PH, Jeung EB, Lee GS. Role of inflammasome regulation on immune modulators. J Biomed Res 2018;32:40I-4I0.

Baggia S, Gravett MG, Witkin SS, Haluska GJ, Novy MJ. InterleukinI beta intra-amniotic infusion induces tumor necrosis factor-alpha, prostaglandin production, and preterm contractions in pregnant rhesus monkeys. J Soc Gynecol Investig 1996;3:121-126.

Baker JM, Chase DM, Herbst-Kralovetz MM. Uterine microbiota: residents, tourists, or invaders? Front Immunol 2018;9:208.

Banerjee P, Jana SK, Pasricha P, Ghosh S, Chakravarty B, Chaudhury K. Proinflammatory cytokines induced altered expression of cyclooxygenase-2 gene results in unreceptive endometrium in women with idiopathic recurrent spontaneous miscarriage. Fertil Steril 2013;99: 179-187.

Behrman RE, Butler AS (eds). Preterm Birth: Causes, Consequences, and Prevention. Washington, DC: National Academic Press, 2007, (Societal costs of preterm birth).

Blackburn PE, Simpson CV, Nibbs RJ, O'Hara M, Booth R, Poulos J et al. Biochem J 2004;379:263-272.

Bonecchi R, Borroni EM, Anselmo A, Doni A, Savino B, Mirolo M, Fabbri M, Jala VR, Haribabu B, Mantovani A et al. Regulation of D6 chemokine scavenging activity by ligand- and Rab I I-dependent surface up-regulation. Blood 2008; I I 2:493-503.

Bonecchi R, Locati M, Galliera E, Vulcano M, Sironi M, Fra AM, Gobbi $M$, Vecchi A, Sozzani S, Haribabu B et al. Differential recognition and scavenging of native and truncated macrophage-derived chemokine (macrophage-derived chemokine/CC chemokine ligand 22) by the D6 decoy receptor. J Immunol 2004; I 72:4972-4976.

Borroni EM, Cancellieri C, Vacchini A, Benureau Y, Lagane B, Bachelerie F, Arenzana-Seisdedos F, Mizuno K, Mantovani A, Bonecchi $\mathrm{R}$ et al. $\beta$-arrestin-dependent activation of the cofilin pathway is required for the scavenging activity of the atypical chemokine receptor D6. Sci Signal 2013;6:SI-S3.

Camilleri M. Leaky gut: mechanisms, measurement and clinical implications in humans. Gut 2019;68:1516-1526.

Charo IF, Ransohoff RM. The many roles of chemokines and chemokine receptors in inflammation. N Engl J Med 2006;354: 610-621.

Chen GY, Nunez G. Sterile inflammation: sensing and reacting to damage. Nat Rev Immunol 20 I0; 1 0:826-837.

Cho GJ, Lee ES, Jin HM, Lee JH, Kim YS, Oh MJ, Seol HJ, Hong SC, Kim HJ. Placental expression of D6 decoy receptor in preeclampsia. Obstet Gynecol Sci 20 15;58:333-339.

Daskalakis G, Thomakos N, Papapanagiotou A, Papantoniou N, Mesogitis S, Antsaklis A. Amniotic fluid interleukin-18 at midtrimester genetic amniocentesis: relationship to intraamniotic microbial invasion and preterm delivery. BJOG 2009; I l 6: |743-1748.

D’lppolito S, Tersigni C, Marana R, Di Nicuolo F, Gaglione R, Rossi ED, Castellani R, Scambia G, Di Simone N. Inflammosome in the human endometrium: further step in the evaluation of the "maternal side". Fertil Steril 20 16; 1 05: I I I-I I8.

Duley L, Meher S, Abalos E. Management of pre-eclampsia. BMJ 2006;332:463-468.

El-Shazly S, Makhseed M, Azizieh F, Raghupathy R. Increased expression of pro-inflammatory cytokines in placentas of women undergoing spontaneous preterm delivery or premature rupture of membranes. Am J Reprod Immunol 2004;52:45-52.

Esplin MS, Romero R, Chaiworapongsa T, Kim YM, Edwin S, Gomez R, Mazor M, Adashi EY. Monocyte chemotactic protein-I is increased in the amniotic fluid of women who deliver preterm in the presence or absence of intra-amniotic infection. J Matern Fetal Neonatal Med 2005; I 7:365-373.

Faro J, Romero R, Schwenkel G, Garcia-Flores V, ArenasHernandez M, Leng Y, Xu Y, Miller D, Hassan SS, Gomez-Lopez N. Inflammation-induced intra-amniotic inflammation induces preterm birth by activating the NLRP3 inflammasome. Biol Reprod 2019; 100:1290-1305. 
Ford HB, Schust DJ. Recurrent pregnancy loss: etiology, diagnosis, and therapy. Rev Obstet Gynecol 2009;2:76-83.

Fra AM, Locati M, Otero K, Sironi M, Signorelli P, Massardi ML, Gobbi M, Vecchi A, Sozzani S, Mantovani A. Cutting edge: scavenging of inflammatory CC chemokines by the promiscuous putatively silent chemokine receptor D6. J Immunol 2003;I70: 2279-2282.

Galliera E, Jala VR, Trent JO, Bonecchi R, Signorelli P, Lefkowitz RJ, Mantovani A, Locati M, Haribabu B. Beta-Arrestin-dependent constitutive internalization of the human chemokine decoy receptor D6. J Biol Chem 2004;279:25590-25597.

Ganguly S, Saxena R, Chattopadhyay A. Reorganization of the actin cytoskeleton upon G-protein coupled receptor signaling. Biochim Biophys Acta 201 1; 1808:1921-1929.

Gargano JW, Holzman C, Senagore P, Thorsen P, Skogstrand K, Hougaard DM, Rahbar MH, Chung H. Mid-pregnancy circulating cytokine levels, histologic chorioamnionitis and spontaneous preterm birth. J Reprod Immunol 2008;79: I00-II0.

Goldenberg RL, Culhane JF, lams JD, Romero R. Epidemiology and causes of preterm birth. Lancet 2008;37 I:75-84.

Gomez-Lopez N, Romero R, Garcia-Flores V, Leng Y, Miller D, Hassan SS, Hsu CD, Panaitescu B. Inhibition of the NLRP3 inflammasome can prevent sterile intra-amniotic inflammation, preterm labor/birth, and adverse neonatal outcomes. Biol Reprod 2019;100: 1306-1318.

Gomez-Lopez N, Romero R, Xu Y, Plazyo O, Unkel R, Leng Y, Than NG, Chaiworapongsa T, Panaitescu B, Dong $Z$ et al.A role for the inflammasome in spontaneous preterm labor with acute histologic chorioamnionitis. Reprod Sci 2017;24:1382-1401.

Gotsch F, Romero R, Chaiworapongsa T, Erez O, Vaisbuch E, Espinoza J, Kusanovic JP, Mittal P, Mazaki-Tovi S, Kim CJ et al.. J Matern Fetal Neonatal Med 2008;2 I:605-616.

Gowri V, Al-Zakwani I. Prevalence of cesarean delivery in preeclamptic patients with elevated uric acid. Hypertens Pregnancy 2010;29:231-235.

Gravett MG, Witkin SS, Haluska GJ, Edwards JL, Cook MJ, Novy MJ. An experimental model for intraamniotic infection and preterm labor in rhesus monkeys. Am J Obstet Gynecol 1994; I 1 I:1660-1667.

Hamilton SA, Tower CL, Jones RL. Identification of chemokines associated with the recruitment of decidual leukocytes in human labour: potential novel targets for preterm labour. PLoS One 20I3;8:e56946.

Hua R, Pease JE, Sooranna SR, Viney JM, Nelson SM, Myatt L, Bennett $P R$, Johnson MR. Stretch and inflammatory cytokines drive myometrial chemokine expression via NF-kappaB activation. Endocrinology 20|2; | 53:48|-49|.

Jacobsson B, Holst RM, Andersson B, Hagberg H. Monocyte chemotactic protein-2 and -3 in amniotic fluid: relationship to microbial invasion of the amniotic cavity, intra-amniotic inflammation and preterm delivery. Acta Obstet Gynecol Scand 2005;84: 566-57I.

Jacobsson B. Intra-amniotic infection and inflammation in preterm birth-is bacteria always the connection? Commentary on the article by Miralles et al. on page 570. Pediatr Res 2005;57:473-474.

Jenkins C, Roberts J, Wilson R, MacLean MA, Shilito J, Walker JJ. Evidence of a ThI type response associated with recurrent miscarriage. Fertil Steril 2000;73:1206-1208.
Khan KS, Wojdyla D, Say L, Gulmezoglu AM, Van Look PF. WHO analysis of causes of maternal death: a systematic review. Lancet 2006;367: 1066-1074.

Khan RN, Hay DP. A clear and present danger: inflammasomes DAMPing down disorders of pregnancy. Hum Reprod Update 20I5;2I:388-405.

Kohli S, Ranjan S, Hoffmann J, Kashif M, Daniel EA, AI-Dabet MM, Bock F, Nazir S, Huebner H, Mertens PR et al. Maternal extracellular vesicles and platelets promote preeclampsia via inflammasome activation in trophoblasts. Blood 2016; 1 28:2 I 53-2164.

Koopmans CM, Zwart JJ, Groen H, Bloemenkamp KW, Mol BW, Van Pampus MG, Van Roosmalen J. Risk indicators for eclampsia in gestational hypertension or mild preeclampsia at term. Hypertens Pregnancy 2011;30:433-446.

Lamkanfi M, Sarkar A, Vande Walle L, Vitari AC, Amer AO, Wewers MD, Tracey KJ, Kanneganti TD, Dixit VM. Inflammasomedependent release of the alarmin HMGBI in endotoxemia. J Immunol 2010; I 85:4385-4392.

Lappas M. Nuclear factor-kappaB mediates placental growth factor induced pro-labour mediators in human placenta. Mol Hum Reprod 20I2; I 8:354-36I.

Liu L, Oza S, Hogan D, Perin J, Rudan I, Lawn JE, Cousens S, Mathers C, Black RE. Global, regional, and national causes of child mortality in 2000-13, with projections to inform post-20I 5 priorities: an updated systematic analysis. Lancet 20I5;385:430-440.

Locati M, Torre YM, Galliera E, Bonecchi R, Bodduluri H, Vago G, Vecchi A, Mantovani A. Silent chemoattractant receptors: D6 as a decoy and scavenger receptor for inflammatory CC chemokines. Cytokine Growth Factor Rev 2005; 1 6:679-686.

Lotze MT, Deisseroth A, Rubartelli A. Damage associated molecular pattern molecules. Clin Immunol 2007; I 24: I-4.

Lubow JM, How HY, Habli M, Maxwell R, Sibai BM. Indications for delivery and short-term neonatal outcomes in late preterm as compared with term births. Am J Obstet Gynecol 2009;200: e30-e33.

Luster AD. Chemokines-chemotactic cytokines that mediate inflammation. N Engl J Med 1998;338:436-445.

Madigan J, Freeman DJ, Menzies F, Forrow S, Nelson SM, Young A, Sharkey A, Moffett A, Graham GJ, Greer IA et al. Chemokine scavenger D6 is expressed by trophoblasts and aids the survival of mouse embryos transferred into allogeneic recipients. J Immunol 2010; 1 84:3202-3212.

Mantovani A, Bonecchi R, Locati M. Tuning inflammation and immunity by chemokine sequestration: decoys and more. Nat Rev Immunol 2006;6:907-918.

Manuck TA, Sheng X, Yoder BA, Varner MW. Correlation between initial neonatal and early childhood outcomes following preterm birth. Am J Obstet Gynecol 20 14;2 1 0:426.

Mariathasan S, Weiss DS, Newton K, McBride J, O'Rourke K, RooseGirma M, Lee WP, Weinrauch Y, Monack DM, Dixit VM. Cryopyrin activates the inflammasome in response to toxins and ATP. Nature 2006;440:228-232.

Martin JA, Martin MPH, Hamilton BE, Osterman MJK. Births in the United States, 2015. NCHS Data Brief No. 258, 2016. http:// www.cdc.gov/nchs/data/databriefs/db258.pdf (September 2016, date last accessed). 
Martinez de la Torre $Y$, Buracchi C, Borroni EM, Dupor J, Bonecchi R, Nebuloni M, Pasqualini F, Doni A, Lauri E, Agostinis C et al. Protection against inflammation- and autoantibody-caused fetal loss by the chemokine decoy receptor D6. Proc Natl Acad Sci USA 2007; 1 04:2319-2324.

Martinon F, Burns K, Tschopp J. The inflammasome: a molecular platform triggering activation of inflammatory caspases and processing of prolL-beta. Mol Cell 2002; 10:417-426.

Matzinger P. An innate sense of danger. Semin Immunol 1998; 10: 399-4I5.

Moffett-King A. Natural killer cells and pregnancy. Nat Rev Immunol 2002;2:656-663.

Mor G, Cardenas I, Abrahams V, Guller S. Inflammation and pregnancy: the role of the immune system at the implantation site. Ann N Y Acad Sci 201 I; | 22 I:80-87.

Mulla MJ, Myrtolli K, Potter J, Boeras C, Kavathas PB, Sfakianaki AK, Tadesse S, Norwitz ER, Guller S, Abrahams VM. Uric acid induces trophoblast IL-I $\beta$ production via the inflammasome: implications for the pathogenesis of preeclampsia. Am J Reprod Immunol 201।;65:542-548.

Murphy PM. The molecular biology of leukocyte chemoattractant receptors. Annu Rev Immunol 1994; I 2:593-633.

Murphy PM, Baggiolini M, Charo IF, Hébert CA, Horuk R, Matsushima K, Miller LH, Oppenheim JJ, Power CA. International union of pharmacology, XXII. Nomenclature for chemokine receptors. Pharmacol Rev 2000;52:|45-176.

Mwaniki MK, Atieno M, Lawn JE, Newton CR. Long-term neurodevelopmental outcomes after intrauterine and neonatal insults: a systematic review. Lancet 2012;379:445-452.

Nibbs RJ, Wylie SM, Yang J, Landau NR, Graham GJ. Cloning and characterization of a novel promiscuous human beta-chemokine receptor D6. J Biol Chem 1997;272:32078-32083.

Nibbs RJ, Kriehuber E, Ponath PD, Parent D, Qin S, Campbell JD, Henderson A, Kerjaschki D, Maurer D, Graham GJ et al. The betachemokine receptor D6 is expressed by lymphatic endothelium and a subset of vascular tumors. Am J Pathol 200 I; 1 58:867-877.

Oppenheim JJ, Yang D. Alarmins: chemotactic activators of immune responses. Curr Opin Immunol 2005; I 7:359-365.

Pacifico F, Lepore A, Mellone S, Sanguigno L, Federico G, Greco A, Brunetti A, Leonardi A. The chemokine scavenging receptor D6/ACKR2 is a target of miR-146a in thyroid cancer. Genes Cancer 2017;8:577-588.

Pearce BD, Garvin SE, Grove J, Bonney EA, Dudley DJ, Schendel DE, Thorsen P. Serum macrophage migration inhibitory factor in the prediction of preterm delivery. Am J Obstet Gynecol 2008; 1 99:4 I-46.

Plazyo O, Romero R, Unkel R, Balancio A, Mial TN, Xu Y, Dong Z, Hassan SS, Gomez-Lopez N. HMGBI induces an inflammatory response in the chorioamniotic membranes that is partially mediated by the inflammasome. Biol Reprod 2016;95:130.

Presicce P, Senthamaraikannan P, Alvarez M, Rueda CM, Cappelletti M, Miller LA, Job AH, Chougnet CA, Kallapur SG. Neutrophil recruitment and activation in decidua with intra-amniotic IL- I beta in the preterm rhesus macaque. Biol Reprod 2015;92:56.

Raghupathy R, Makhseed M, Azizieh F, Omu A, Gupta M, Farhat R. Cytokine production by maternal lymphocytes during normal human pregnancy and in unexplained recurrent spontaneous abortion. Hum Reprod 2000; 15:713-718.
Redman CW, Sargent IL. Latest advances in understanding preeclampsia. Science 2005;308: 1592-1594.

Redman CW, Sargent IL. Pre-eclampsia, the placenta and the maternal systemic inflammatory response-a review. Placenta 2003;24: S2I-S27.

Redman CW, Sacks GP, Sargent IL. Preeclampsia: an excessive maternal inflammatory response to pregnancy. Am J Obstet Gynecol 1999; | 80:499-506.

Redman CW, Sargent IL, Staff AC. IFPA Senior Award Lecture: making sense of pre-eclampsia-two placental causes of preeclampsia? Placenta 2014;35:S20-S25.

Romero R, Chaemsaithong P, Korzeniewski SJ, Tarca AL, Bhatti G, Xu Z, Kusanovic JP, Dong Z, Docheva N, Martinez-Varea A et al. Clinical chorioamnionitis at term II: the intra-amniotic inflammatory response. J Perinat Med 2016;44:5-22.

Romero R, Chaiworapongsa T, Alpay Savasan Z, Xu Y, Hussein Y, Dong Z, Kusanovic JP, Kim CJ, Hassan SS. Damage-associated molecular patterns (DAMPs) in preterm labor with intact membranes and preterm PROM: a study of the alarmin HMGBI. Matern Fetal Neonatal Med 201 I;24: |444-1455.

Romero R, Dey SK, Fisher SJ. Preterm labor: one syndrome, many causes. Science 20I4;345:760-765.

Romero R, Espinoza J, Goncalves LF, Kusanovic JP, Friel L, Hassan S. The role of inflammation and infection in preterm birth. Semin Reprod Med 2007;25:21-39.

Romero R, Miranda J, Chaemsaithong P, Chaiworapongsa T, Kusanovic JP, Dong Z, Ahmed Al, Shaman M, Lannaman K, Yoon BH et al. Sterile and microbial-associated intra-amniotic inflammation in preterm prelabor rupture of membranes. J Matern Fetal Neonatal Med 20I5a;28:|394-|409.

Romero R, Miranda J, Chaiworapongsa T, Chaemsaithong P, Gotsch F, Dong Z, Ahmed Al, Yoon BH, Hassan SS, Kim CJ et al. A novel molecular microbiologic technique for the rapid diagnosis of microbial invasion of the amniotic cavity and intra-amniotic infection in preterm labor with intact membranes. Am J Reprod Immunol 20I4a;7 I:330-358.

Romero R, Miranda J, Chaiworapongsa T, Korzeniewski SJ, Chaemsaithong P, Gotsch F, Dong Z, Ahmed Al, Yoon BH, Hassan SS et al. Prevalence and clinical significance of sterile intra-amniotic inflammation in patients with preterm labor and intact membranes. Am J Reprod Immunol 20 I4b;72:458-474.

Romero R, Miranda J, Kusanovic JP, Chaiworapongsa T, Chaemsaithong P, Martinez A, Gotsch F, Dong Z, Ahmed Al, Shaman $M$ et al. Clinical chorioamnionitis at term I: microbiology of the amniotic cavity using cultivation and molecular techniques. $J$ Perinat Med 2015b;43:19-36.

Sadowsky DW, Adams KM, Gravett MG, Witkin SS, Novy MJ. Preterm labor is induced by intraamniotic infusions of interleukinIbeta and tumor necrosis factor-alpha but not by interleukin-6 or interleukin-8 in a nonhuman primate model. Am J Obstet Gynecol 2006; 195: 1578-1589.

Saito S, Sakai M. Th1/Th2 balance in preeclampsia. J Reprod Immunol 2003;59:161-173.

Sakai M, Sasaki Y, Yoneda S, Kasahara T, Arai T, Okada M, Hosokawa $\mathrm{H}$, Kato K, Soeda Y, Saito S. Elevated interleukin-8 in cervical mucus as an indicator for treatment to prevent premature birth and 
preterm, pre-labor rupture of membranes: a prospective study. Am J Reprod Immunol 2004;5 I:220-225.

Sargent IL, Borzychowski AM, Redman CW. Immunoregulation in normal pregnancy and pre-eclampsia: an overview. Reprod Biomed Online 2006; 1 3:680-686.

Sargent IL, Germain SJ, Sacks GP, Kumar S, Redman CW. Trophoblast deportation and the maternal inflammatory response in pre-eclampsia. J Reprod Immunol 2003;59: I53-160.

Szarka A, Rigó J Jr, Lázár L, Beko G, Molvarec A. Circulating cytokines, chemokines and adhesion molecules in normal pregnancy and preeclampsia determined by multiplex suspension array. BMC Immunol 20I0; I I:59.

Teoh PJ, Menzies FM, Hansell CA, Clarke M, Waddell C, Burton GJ, Nelson SM, Nibbs RJ. Atypical chemokine receptor ACKR2 mediates chemokine scavenging by primary human trophoblasts and can regulate fetal growth, placental structure, and neonatal mortality in mice. J Immunol 2014; 193:5218-5228.

Tersigni C, Di Nicuolo F, Maulucci G, Rolfo A, Giuffrida D, Veglia M, De Spirito M, Scambia G, Todros T, Di Simone N. Placental Chemokine Receptor D6 Is Functionally Impaired in Pre-Eclampsia. PLoS One 2016; I I:e0164747.

Tersigni C, D'lppolito S, Di Nicuolo F, Marana R, Valenza V, Masciullo V, Scaldaferri F, Malatacca F, de Waure C, Gasbarrini A et al. Recurrent pregnancy loss is associated to leaky gut: a novel pathogenic model of endometrium inflammation? J Transl Med 2018; 16:102.

Todros T, Bontempo S, Piccoli E, letta F, Romagnoli R, Biolcati M, Castellucci M, Paulesu L. Increased levels of macrophage migration inhibitory factor (MIF) in preeclampsia. Eur J Obstet Gynecol Reprod Biol 2005; I 23: 162-166.

Weber M, Blair E, Simpson CV, O'Hara M, Blackburn PE, Rot A, Graham GJ, Nibbs RJ. The chemokine receptor D6 constitutively traffics to and from the cell surface to internalize and degrade chemokines. Mol Biol Cell 2004; I 5:2492-2508.

Weel Cl, Romão-Veiga M, Matias ML, Fioratti EG, Peraçoli JC, Borges VT, Araujo JP Jr, Peraçoli MT. Increased expression of NLRP3 inflammasome in placentas from pregnant women with severe preeclampsia. J Reprod Immunol 20 I7; 1 23:40-47.

Wessels JM, Linton NF, Croy BA, Tayade C. A review of molecular contrasts between arresting and viable porcine attachment sites. Am J Reprod Immunol 2007;58:470-480.

Wessels JM, Linton NF, van den Heuvel MJ, Cnossen SA, Edwards AK, Croy BA, Tayade C. Expression of chemokine decoy receptors and their ligands at the porcine maternal-fetal interface. Immunol Cell Biol 201 I;89:304-3।3.

Wilczyński JR. Th1/Th2 cytokines balance-yin and yang of reproductive immunology. Eur J Obstet Gynecol Reprod Biol 2005; I 22: |36-143. 